\title{
Haste to Taste Artificial Intelligence in Psychology: A Short Critique Plus an Easy Policy
}

\author{
Reza Rastmanesh* \\ Independent Researcher, Private Clinic, Iran \\ *Corresponding author: Reza Rastmanesh, Independent Researcher, Private Clinic, Tehran, Iran; Member of the American Physical \\ Society, USA; Member of The Nutrition Society, London, UK.
}

To Cite This Article: Reza Rastmanesh. Haste to Taste Artificial Intelligence in Psychology: A Short Critique Plus an Easy Policy. A Review. Am J Biomed Sci \& Res. 2021 - 11(6). AJBSR.MS.ID.001687. DOI: 10.34297/AJBSR.2021.11.001687.

Received: 眥 December 10, 2020; Published: 眥 February 04, 2021

\section{Introduction}

Application of artificial intelligence (AI) in psychology and psychotherapy (and vice versa) has gained extraordinary interest in recent years. Yet, there are sparse efforts (if any) to enter robotics, AI and computer in experimental designs of psychology and psychotherapy studies. Fixed design, as the saying goes, replicate similar results. However, in psychological studies, this is not always the case. This is important because there is a mutual crosstalk between psychology experiments and psychotherapy practice in most cases; experiments provide scientific basis for the best practice, in principle.

In most experiment designs, human observers are involved as the experimenter or the interpreter. In Scavenger Hunt Game [1], Word Game [2], Magic Square Game [3], judgment/decision making experiments [4], cursor tracking tasks to investigate human behavior modeling and developing models to predict human intention, and a broad array of similar games and experiments [5-9], noise effects of observer/experimenter hugely confound the implementation of the game/experiment, analysis of data and interpretation of the results. Indeed, results of some experiments are used for some critical issues such as driver behavior, which directly deals with death and life [5] not for amusement.

One solution to remove such human agent-induced noises could be using the robots and computers. Application of Intelligent RobotBased Design (IRBD) to model human behaviors in experimental settings can become a reality soon. The irony is that appetite to use $\mathrm{AI}$ and robots in psychology is so high that before intelligent robots prove their efficacy at experimental level, most of proposals are focused on approaches to reconcile between psychotherapy and AI, to a level that their application as therapist has rightly raised some ethical questions in the scientific community and general public
[10]. This is while a careful search in web and scientific engines reveal that total number of published papers on application of AI in psychology and psychotherapy far overweigh the number of basic experiments conducted in the field.

There is an annoying lack of literature on application of $\mathrm{AI}$ and robots to replicate previous studies in order to compare the consistency between human observer-based designs with that of IRBD-based designs, To the best of author's knowledge, there is no recognized and formal tribune for such studies (if any).

A good policy could be a proper budgeting and a "call for papers" on an international-scale and to encourage researchers to fill the gaps in the literature. Alternatively, respected journals may announce some volumes for these thematic issues.

That would be ancillary to shape panels of experts and expert committees to provide consultations via web training on designs of experiments and topics of investigations to lead these efforts costeffectively and most practically.

\section{References}

1. Eric NS, Sahr M, Young M, Axford K, Sohn M, Lyons M, et al. (2020) Design of a large-scale escape room for first-year pharmacy student orientation. Curr Pharm Teach Learn 12(11): 1340-1347.

2. Faria M (2020) Word games and molecular recognition - The creative control of endothelial cell function. Biosystems 187: 104041.

3. Pawela u, Gawron P, Pucha_éa Z, S_éadkowski J (2013) Enhancing pseudo-telepathy in the magic square game. PloS one 8(6): e64694.

4. Giubilini A, Savulescu J (2018) The Artificial Moral Advisor. The "Ideal Observer" Meets Artificial Intelligence. Philos Technol 31(2): 169-188.

5. Brewster SE, Elliott MA, Kelly SW (2015) Evidence that implementation intentions reduce drivers' speeding behavior: testing a new intervention to change driver behavior. Accid Anal Prev 74: 229-242. 
6. Degenhart AD, Bishop WE, Oby ER, Tyler-Kabara EC, Chase SM, et al. (2020) Stabilization of a brain-computer interface via the alignment of low-dimensional spaces of neural activity. Nat Biomed Eng 4(7): 672685.

7. Lee S, Yoo J, Han G (2015) Gaze-Assisted User Intention Prediction for Initial Delay Reduction in Web Video Access. Sensors (Basel) 15(6): 14679-14700.

8. Merel J, Carlson D, Paninski L, Cunningham JP (2016) Neuroprosthetic Decoder Training as Imitation Learning. PLoS Comput Biol 12(5): e1004948.
9. Verros S, Lucassen K, Hekman EEG, Bergsma A, Verkerke GJ, et al. (2019) Evaluation of intuitive trunk and non-intuitive leg sEMG control interfaces as command input for a 2-D Fitts's law style task. PloS one 14(4): e0214645.

10. Fiske A, Henningsen P, Buyx A (2019) Your Robot Therapist Will See You Now: Ethical Implications of Embodied Artificial Intelligence in Psychiatry, Psychology, and Psychotherapy. J Med Internet Res 21(5): e13216. 